\title{
Minat Pembelajaran Menggunakan E-Learning Mata Kuliah Kinesiologi Pada Mahasiswa
}

\author{
DESTRIANI \\ Prodi Pendidikan Jasmani dan Kesehatan, FKIP Universitas Sriwijaya \\ destriani@fkip.unsri.ac.id
}

\begin{abstract}
ABSTRAKS
Penelitian ini bertujuan mengetahui minat pembelajaran menggunakan elearning mata kuliah kinesiologi pada mahasiswa Penjaskes Fakultas Keguruan dan IImu Pendidikan Universitas Sriwijaya. Bentuk penelitian ini adalah penelitian survei. Populasi penelitian adalah mahasiswa semester 3 Program Studi Pendidikan Jasmani dan Kesehatan kelas Indralaya, sampel penelitian yaitu seluruh mahasiswa semester 3 kelas Indralaya yang berjumlah 44 orang. Alat pengumpulan data yaitu angket minat belajar. Hasil analisis data diperoleh minat belajar mahasiswa menggunakan e-learning yaitu $86,38 \%$ dan masuk pada kategori sangat baik. Hal ini menunjukkan penggunaan e learning dapat meningkatkan minat belajar mahasiswa dan dapat meningkatkan hasil belajar mahasiswa pada mata kuliah kinesiologi.
\end{abstract}

Kata kunci : minat belajar, e-learning, kinesiology. 


\section{PENDAHULUAN}

Standar Nasional Pendidikan Tinggi bertujuan untuk menjamin tercapainya tujuan pendidikan tinggi yang berperan strategis dalam mencerdaskan kehidupan bangsa, memajukan ilmu pengetahuan dan teknologi dengan menerapkan nilai humaniora serta pembudayaan dan pemberdayaan bangsa Indonesia yang berkelanjutan dan menjamin agar pembelajaran pada program studi, penelitian, dan pengabdian kepada masyarakat yang diselenggarakan oleh perguruan tinggi di seluruh wilayah hukum Negara Kesatuan Republik Indonesia mencapai mutu sesuai dengan kriteria yang ditetapkan dalam Standar Nasional Pendidikan Tinggi (Permenristekdikti, 2015).

Peranan media pembelajaran sangat penting dalam upaya meningkatkan hasil belajar peserta didik. Seiring dengan perkembangan era globalisasi, pelaksanaan pembelajaran saat ini perlu didukung dengan media pembelajaran yang berbasis teknologi modern (Smaldino et al, 2008). Kategori dasar dari media meliputi "tes audio, visual, video, manipulasi, dan subyek. Media berbasis teknologi modern selain dapat meningkatkan minat belajar siswa juga mampu melatih siswa untuk beradaptasi dengan arus perkembangan di bidang teknologi informasi (Smaldino et al, 2008). Salah satu inovasi media pembelajaran yang dapat dijadikan sebagai penunjang proses pembelajaran adalah dalam bentuk e-learning. Elearning merupakan istilah populer dalam pembelajaran online berbasis internet, teknologi elearning ini dihubungkan atau dibantu oleh teknologi internet, serta membutuhkan sebuah media untuk dapat menampilkan materi pelajaran dan pertanyaan yang membutuhkan fasilitas komunikasi untuk dapat saling bertukar informasi (Prasojo \& Riyanto, 2011).

Menurut (Hamalik, 2001) menyatakan bahwa minat adalah perubahan energi dalam diri (pribadi) seseorang yang ditandai dengan timbulnya perasaan dan reaksi untuk mencapai tujuan. Minat belajar mahasiswa di pogram studi Pendidikan Jasmani dan Kesehatan masih terbilang kurang, hal ini terlihat dari masih ada mahasiswa yang pasif dalam pembelajaran, tidak semangat dan bosan, karena pembelajaran selama ini yang terjadi masih bersifat tatap muka di kelas, belum dilakukan secara online di luar kelas, oleh karena itu peneliti menerapkan pembelajaran menggunakan media e-learning agar mahasiswa menjadi berminat untuk belajar yang dapat terjadi dimana dan kapan saja tanpa batasan ruang dan waktu serta dapat memanfaat kan media yang menjadi sumber belajar dari mahasiswa.

Psikologi belajar yang melandasi pemakaian media dan teknologi dalam belajar dapat ditinjau dari empat perspektif yaitu behaviorist perspective, cognitivist perspective, constructivist prespective, and social psychological perspective, behaviorist perspective, memandang belajar sebagai perubahan tingkah laku sebagai akibat adanya interaksi antara stimulus dan respon cognitivist perspective, memandang hasil belajar bukan hanya melibatkan stimulus dan respon, namun mementingkan pula proses belajar dari pada hasil belajar (Heinich et al, 2006). Pembelajaran diperlukan refleksi, dapat menggunakan berbagai media ajar selama pembelajaran untuk melihat seberapa proses pembelajaran telah tercapai (Saribas \& Ceyhan, 2015). Sesuai dengan pendapat di atas dengan media ajar dapat mengatasi hambatan-hambatan yang terjadi dalam proses pembelajaran, selain itu dengan adanya media ajar dapat merangsang pikiran, perasaan, perhatian, dan minat belajar siswa untuk aktif dalam belajar sehingga proses pembelajaran dapat berjalan lebih efektif dan efesien mencapai sasaran yang dituju. Dipilinnya mata kuliah Kinesiologi untuk pembelajaran e-learning, karena dianggap sesuai dengan media yang akan diterapkan dengan e-learning, agar mahasiwa tidak hanya mengerti materi mata kuliah e-learning namun juga dapat mengimplentasikan pembelajaranya menggunakan media e-learning. Diharapkan dengan pembelajaran menggunakan media e-Learning pada mata kuliah Kinesilogi e-learning di Prodi Pendidikan Jasmani Dan Kesehatan dapat berdampak pada 
minat belajar mahasiswa yang meningkat sehingga menjadi termotivasi dalam pembelajaran serta dapat mengerti dengan materi yang diajarkan.

\section{METODE PENELITIAN}

Penelitian ini dilaksanakan oleh Dosen Program Studi Pendidikan Jasmani dan Kesehatan FKIP Universitas Sriwijaya yang mengampuh mata kuliah kinesiologi. Penelitian ini dilaksanakan pada Februari 2017. Populasi dalam penelitian ini adalah seluruh mahasiswa semester 3 yang mengambil mata kuliah Kinesiologi yang berjumlah 70 orang yang terdiri dari kelas Indralaya dan kelas Palembang. Jumlah kelas Indralaya dengan jumlah 44 dan kelas Palembang berjumlah 30 orang. Sampel yang dipilih yaitu kelas yang menggunakan pembelajaran kinesiologi secara e-learning, yaitu kelas Indralaya yang berjumlah 44 orang. Pengumpulan data yang digunakan dalam penelitian ini adalah angket untuk mendapatkan data minat belajar mahsiswa. Untuk melihat hasil minat belajar siswa digunakan rumus persentase dari hasil pengumpulan data menggunakan angket.

Pengumpulan data dalam penelitian ini menggunakan angket dan dokumentasi untuk memperoleh data tingkat kelulusan mahasiswa dalam mata kuliah kinesiologi , angket yang digunakan tersaji pada Tabel 1 dengan bobot jawaban yang diberikan menggunakan skala Likert seperti pada Tabel.

Tabel 1. Instrumen Kisi-Kisi Angket Minat Belajar (Slameto, 2010)

\begin{tabular}{|c|l|l|}
\hline No & \multicolumn{1}{|c|}{ Indikator } & \multicolumn{1}{c|}{ Sub indikator } \\
\hline 1 & Ketertarikan & Responsif \\
\hline 2 & Perhatian & Konsentrasi \\
\hline 3 & Kesukaan & $\begin{array}{l}\text { Gairah } \\
\text { Inisiatif }\end{array}$ \\
\hline 4 & Keterlibatan & $\begin{array}{l}\text { Kemauan } \\
\text { Kerja keras }\end{array}$ \\
\hline
\end{tabular}

Sampel angket yang digunakan untuk melihat minat belajar mahasiswa seperti di bawah ini:

Tabel 2. ANGKET MINAT BELAJAR MAHASISWA PADA MATA KULIAH KINESIOLOGI

\begin{tabular}{|c|c|c|c|c|c|}
\hline NO & PERNYATAAN & SS & $\mathbf{S}$ & TS & STS \\
\hline 1 & Saya bertanya kepada dosen bila saya tidak mengerti & & & & \\
\hline 2 & $\begin{array}{l}\text { Saya akan bertanya bila kurang jelas dengan materi yang diajarkan } \\
\text { dosen. }\end{array}$ & & & & \\
\hline 3 & Tiap malam saya belajar untuk materi besok pagi. & & & & \\
\hline 4 & $\begin{array}{l}\text { Saya mencatat materi-materi pokok jika dosen menjelaskan, agar } \\
\text { nanti saya lebih faham. }\end{array}$ & & & & \\
\hline 5 & Saya tidak tertarik pada perkuliahan dengan sistem presentasi & & & & \\
\hline 6 & $\begin{array}{l}\text { Saya mengajak kawan-kawan belajar kelompok, bila mengalami } \\
\text { kesulitan belajar. }\end{array}$ & & & & \\
\hline 7 & Saya belajar dirumah setiap malam? & & & & \\
\hline 8 & Perkuliahan lebih asik bila di luar ruangan/ dialam terbuka. & & & & \\
\hline 9 & Suasana kampus sangat mendukung kegiatan perkuliahan. & & & & \\
\hline 10 & Saya akan hadir ke kampus walaupun hujan deras & & & & \\
\hline 11 & Dengan belajar saya percaya akan menambah wawasan saya & & & & \\
\hline 12 & Rasa ingin tahu dapat menumbuhkan motivasi belajar pada diri saya & & & & \\
\hline 13 & Perhatian saya sangat besar dalam belajar & & & & \\
\hline
\end{tabular}




\begin{tabular}{|c|c|c|c|c|c|}
\hline NO & PERNYATAAN & SS & $\mathbf{S}$ & TS & STS \\
\hline 14 & Perhatihan belajar saya menjadi hilang apabila ada keributan di kelas & & & & \\
\hline 15 & Saya senang belajar hal-hal baru yang belum saya tau sebelumnya & & & & \\
\hline 16 & $\begin{array}{l}\text { Perhatian saya lebih tertuju pada dosen yang menggunakan metode } \\
\text { pembelajaran yang menarik }\end{array}$ & & & & \\
\hline 17 & Perhatian saya sangat besar dalam belajar & & & & \\
\hline 18 & Saya sering mendiskusikan hal yang baru bersama teman-teman & & & & \\
\hline 19 & Saya menyimak pelajaran dengan baik saat kegiatan pembelajaran & & & & \\
\hline 20 & Saya merasa senang saat dosen hadir dan mengajar mata kuliah ini & & & & \\
\hline 21 & Materi yang diajarkan dalam mata kuliah ini bermanfaat bagi saya & & & & \\
\hline 22 & Saya punya keinginan agar jam mata kuliah ini ditambah & & & & \\
\hline 24 & Saya punya keinginan agar jam mata kuliah ini dipercepat & & & & \\
\hline 25 & Saya mengulangi mata kuliah ini setelah pulang dari kampus & & & & \\
\hline 26 & Saya memperhatikan penjelasan dosen tentang mata kuliah ini & & & & \\
\hline 27 & Saya aktif saat pembelajaran diskusi berlangsung & & & & \\
\hline 28 & Saya mengikuti semua kuis online yang selalu diberikan & & & & \\
\hline
\end{tabular}

Dokumentasi kelulusan sampel penelitian,seperti di bawah ini:

Tabel 3. DAFTAR NILAI AKHIR SEMESTER

\begin{tabular}{|c|l|c|c|c|c|c|}
\hline NO. & \multicolumn{1}{|c|}{ NAMA MAHASISWA } & NTR & NUTS & NUAS & NA & NA \\
(Angka) & (Huruf) \\
\hline 1. & VWP & & & & & \\
\hline 2. & IGKA & 80 & 85 & 80 & 81.75 & B \\
\hline 3. & FA & 80 & 80 & 85 & 82 & B \\
\hline 4. & DDC & 85 & 85 & 80 & 83 & B \\
\hline 5. & CKS & 90 & 90 & 90 & 90 & A \\
\hline 6. & TWA & 80 & 80 & 80 & 80 & B \\
\hline 7. & JP & 80 & 85 & 85 & 83.75 & B \\
\hline 8. & EA & 75 & 85 & 85 & 82.5 & B \\
\hline 9. & EHP & 80 & 80 & 80 & 80 & B \\
\hline 10. & RM & 85 & 80 & 80 & 81.25 & B \\
\hline 11. & M & 95 & 90 & 90 & 91.25 & A \\
\hline 12. & PIS & 85 & 90 & 90 & 88.75 & A \\
\hline
\end{tabular}




\begin{tabular}{|c|c|c|c|c|c|c|}
\hline 13. & NP & 80 & 85 & 85 & 83.75 & $B$ \\
\hline 14. & AI & 80 & 80 & 80 & 80 & $B$ \\
\hline 15. & AP & 80 & 85 & 80 & 81.75 & $B$ \\
\hline 16. & MNI & 85 & 85 & 80 & 83 & B \\
\hline 17. & $P$ & 70 & 70 & 70 & 70 & C \\
\hline 18. & $\mathrm{MH}$ & 90 & 90 & 95 & 92 & $A$ \\
\hline 19. & $\mathrm{KJ}$ & 80 & 80 & 80 & 80 & $B$ \\
\hline 20. & A & 85 & 85 & 80 & 83 & $B$ \\
\hline 21. & VA & 80 & 80 & 85 & 82 & B \\
\hline 22. & SRW & 80 & 80 & 80 & 80 & $B$ \\
\hline 23. & MTS & 85 & 85 & 80 & 83 & $B$ \\
\hline 24. & GPD & 80 & 80 & 85 & 82 & $B$ \\
\hline 25. & ER & 70 & 70 & 70 & 70 & C \\
\hline 26. & MPY & 85 & 80 & 80 & 81.25 & B \\
\hline 27. & WIS & 86 & 86 & 86 & 86 & A \\
\hline 28. & AK & 80 & 80 & 80 & 80 & $B$ \\
\hline 29. & AW & 85 & 80 & 80 & 81.25 & B \\
\hline 30. & HDS & 70 & 70 & 70 & 70 & $\mathrm{C}$ \\
\hline 31. & $\mathrm{CP}$ & 80 & 80 & 80 & 80 & $B$ \\
\hline 32. & $S$ & 80 & 85 & 85 & 83.75 & $B$ \\
\hline 33. & DNK & 80 & 80 & 80 & 80 & $B$ \\
\hline 34. & TARP & 85 & 85 & 85 & 85 & $B$ \\
\hline 35. & RLS & 85 & 80 & 80 & 81.25 & $B$ \\
\hline 36. & MABP & 80 & 75 & 80 & 78.25 & $B$ \\
\hline 37. & DL & 85 & 80 & 75 & 79.25 & $B$ \\
\hline 38. & $M N$ & 75 & 80 & 80 & 78.75 & $B$ \\
\hline 39. & MRR & 80 & 80 & 75 & 78 & $B$ \\
\hline
\end{tabular}




\begin{tabular}{|c|l|c|c|c|c|c|}
\hline 40. & PW & 80 & 85 & 80 & 81.75 & B \\
\hline 41. & RMP & 80 & 80 & 75 & 78 & B \\
\hline 42. & WJ & 85 & 90 & 90 & 88.75 & A \\
\hline 43. & PLG & 70 & 70 & 70 & 70 & C \\
\hline 44 & DP & 80 & 80 & 80 & 80 & B \\
\hline
\end{tabular}

\section{HASIL DAN PEMBAHASAN}

Berdasarkan hasil pengumpulan data selama penelitian, data yang diperoleh melalui angket minat belajar mahasiswa yang disajikan berupa tanggapan terhadap pernyataan-pernyataan yaitu menjadi empat kategori yaitu: SS, S, TS dan STS. Kemudian untuk hasil jawaban mahasiswa diperiksa dan selanjutnya diubah menjadi data kuantitatif, sesuai dengan bobot masing-masing jawaban dengan skala likert.

Tabel 4. Hasil Analisis Angket Mahasiswa

\begin{tabular}{|c|l|c|c|c|}
\hline NO & \multicolumn{1}{|c|}{ Indikator } & $\begin{array}{c}\text { Jumlah Data } \\
\text { Angket (44 } \\
\text { Mahasiswa) }\end{array}$ & Persentase (\%) & Kategori \\
\hline 1 & Ketertarikan & 152 & 86,4 & Sangat baik \\
\hline 2 & Perhatian & 149 & 84,6 & Baik \\
\hline 3 & Kesukaan & 151 & 85,5 & Baik \\
\hline 4 & Keterlibatan & 156 & 88,6 & \\
\hline & Jumlah & 608 & 345,1 & Sangat baik \\
\hline & Rerata & 152 & 86,36 & \\
\hline
\end{tabular}

Diperoleh data dari 44 mahasiswa pada indikator ketertatrikan didapat skor 152 dengan persentase $86,4 \%$ dan masuk pada kategori sangat baik, selanjutnya indikator perhatian didapat skor 149 dengan persentase sebesar 84,6\%, dan masuk pada kategori baik, selanjutnya pada indikator kesukaan didapat skor rata-rata 151 dengan persentase sebesar 85,5 \%, dan indikator terakhir yaitu keterlibatan dengan rata-rata skor 156 dengan persentase sebesar $88,6 \%$ dan masuk pada kategori sangat baik, untuk lebih jelas dapat dilihat pada grafik berikut ini: 


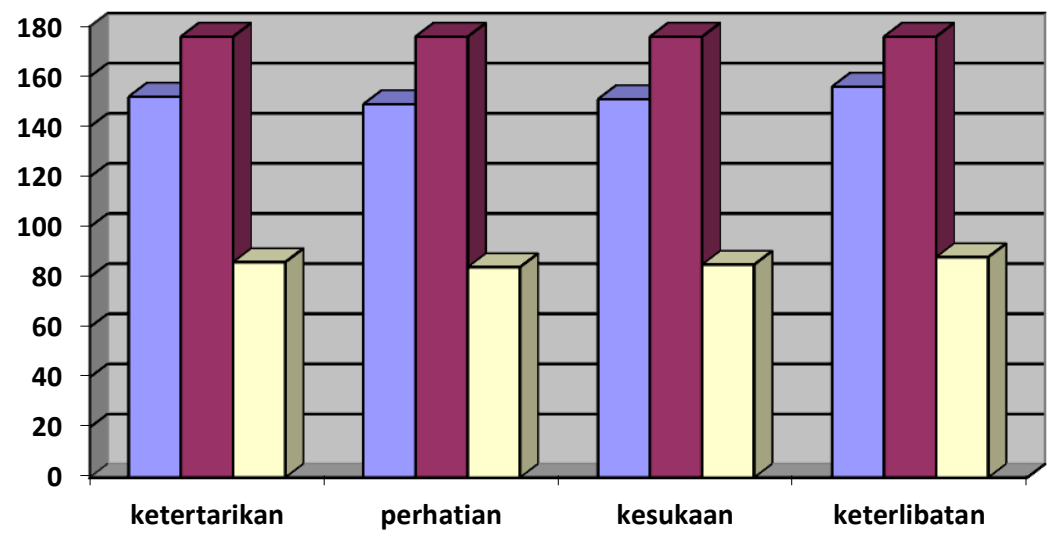

口jumlah angket data

口nilai maksimum

$\square$ persentase

Gambar 1. Hasil Angket Minat Belajar Mahasiswa

Berdasarkan hasil analisis angket mahasiswa di atas maka dapat disimpulkan bahwa secara umum minat belajar mahasiswa termasuk dalam kategori "Sangat baik" dengan persentase rata-rata $86,36 \%$. Dapat dilihat dari rata-rata pesentase dari indikator hasil minat yaitu pada indicator ketertarikan didapat rata-rata persentase sebesar 86,4 dan masuk pada kategori sangat baik, selanjutnya pada indikator perhatian didapat rata-rata persentase sebesar $84,6 \%$ dan masuk pada kategori baik, selanjutnya pada indikator kesukaan didapat rata-rata persentase sebesar $85,5 \%$ dan masuk pada kategori baik, serta pada indikator keterlibatan didapat rata-rata persentase sebesar $88,6 \%$ dan masuk pada kategori sangat baik. Selaras dengan penelitian yang dilakukan (Islami \& Murti, 2016) menyatakan bahwa hasil belajar siswa setelah pemanfaatan media pembelajaran e-learning dapat meningkatkan hasil belajar siswa. Sehingga berdasarkan pendapat di atas minat belajar mahasiswa menggunakan media e learning mata kuliah kinesiologi masuk pada kategori sangat baik. (Mayer, 2012) menyatakan bahwa pesan multimedia pembelajaran adalah sebuah komunikasi yang mengandung kata-kata dan gambar yang dapat mendorong atau mendukung proses pembelajaran, sehingga sesuai dengan pendapat tersebut setiap penggunaan multimedia seperti e-learning dapat mendorong atau mendukung proses pembelajaran.

\section{KESIMPULAN}

Tujuan dalam penelitian ini adalah untuk mengetahui minat pembelajaran menggunakan $e-$ learning mata kuliah kinesiologi pada mahasiswa Prodi Penjaskes. Berdasarkan hasil analis data penelitian yang dilakukan, secara umum dapat disimpulkan bahwa dari hasil analisis data bahwa minat belajar mahasiswa sesudah diajarkan menggunakan media e-learning mata kuliah kinesiologi pada mahasiswa di Prodi Pendidikan Jasmani diperoleh persentase rata-rata sebesar 86,36 \% termasuk dalam kategori "Sangat baik"., sehingga manfaat dalam penelitian ini dapat berupa informasi minat belajar mahasiswa setelah menggunakan pembelajaran e-learning. E-Learning dapat dijadikan sebagai salah satu media untuk meningkatkan minat belajar mahasiswa.

\section{SARAN}

Berdasarkan hasil penelitian yang telah dilakukan, saran yang dapat diberikan sebagai berikut: 
1. E-Learning merupakan salah satu alternatif media pembelajaran interaktif yang mengembangkan sikap aktif, mandiri, dan kreatif, maka sebaiknya media pembelajaran ini dapat digunakan untuk setiap mata kuliah.

2. Untuk penelitian lebih lanjut, sebaiknya melakukan penelitian sejenis tetapi dengan pokok bahasan yang berbeda, serta tambahan fitur-fitur yang lebih lengkap dan menggunakan inovasi terbaru agar dapat dilihat bahwa pemanfaatan media pembelajaran audio-visual berbasis e-learning ini sangat sesuai untuk diterapkan pada proses pembelajaran.

3. Penelitian ini perlu ditindak lanjuti untuk melihat sejauh mana hasil belajar siswa menggunakan media audio-visual berbasis e-learning..

\section{DAFTAR PUSTAKA}

\section{Rujukan Buku:}

Hamalik, O., 2001,Proses Belajar Mengajar,Bumi Aksara, Jakarta.

Heinich, et.al. (2006). Instruction Media and Technologies for Learning. New Jersey : Englewood CliffsKemp Kemp, J. E \& Deane K.D. Planning and Producing Instructional Media. New York : Harper \& Row Publishers Cambridge.

Mayer, Richard E. 2012. Cognitive Theory of Multimedia Learning. California: University of California.

Prasojo, L.D. dan Riyanto. 2011. Teknologi Informasi Pendidikan. Yogyakarta: Gava Media. Permenristekdikti No 44 Tahun 2015 tentang Standar Nasional Pendidikan Tinggi.

Smaldino, Sharon E., Lowther , Deborah L., Russel, James D.. 2008. Instructional Technology and Media for Learning (Ninth Edition). NJ: Pearson Education Inc.

Slameto.(2010). Belajar dan Faktor-Faktor yang Memengaruhinya. Jakarta: Rineka Cipta.

\section{Rujukan Jurnal:}

Lu'lu Dian Islami \& Rina Hari Murti. (2016). Pemanfaatan Media Pembelajaran E-Learning Pada Konten "Eduvidgame" Untuk Meningkatkan Hasil Belajar Siswa Smk Kelas X Pada Mata Pelajaran Perakitan Komputer. Jurnal IT-Edu Volume 01 Nomor 01 137142.

Saribas, D. \& Ceyhan,G.D. (2015). Learning to Teach Scientific Practices: pedagogical decisions and reflections during a course for pre-service science teachers. International Journal of STEM Education 2(7):1-13. 